А.С.Водопьянов ${ }^{1}$, Ю.Н. Хомяков ${ }^{2}$, Р.В. Писанов ${ }^{1}$, А.Ю. Фурина ${ }^{2}$, А.А. Лопатин ${ }^{2}$, A.К.Носков ${ }^{1}$

${ }^{1}$ ФКУЗ Ростовский-на-Дону противочумный институт Роспотребнадзора, 344002, Ростов-на-Дону, Россия;

${ }^{2}$ ФКУЗ «Противочумный центр» Роспотребнадзора, 127490, Москва, Россия

\title{
Разработка программы автоматизированного учета результатов ПЦР- исследований в режиме реального времени в условиях массового поступления биологического материала
}

Для корреспонденции: Хомяков Юрий Николаевич, к.м.н., д.б.н., старший научный сотрудник, заведующий лабораторией, ФКУЗ «Противочумный центр» Роспотребнадзора, 127490, Москва, Россия, khomyakov yuri@mail.ru

For correspondence: Yuri N. Khomyakov, MD, PhD, Dr. Sci. Biol., Head of laboratory of virology Antiplague Center of Rospotrebnadzor, E-mail: khomyakov_yuri@mail.ru

Information about authors:

Vodopyanov AS, https://orcid.org/0000-0002-9056-3231

Khomyakov YN, https://orcid.org/0000-0003-0540-252X

Pisanov RV, https://orcid.org/0000-0002-7178-8021

Furina AY, https://orcid.org/0000-0002-0801-0655

Lopatin AA, https://orcid.org/0000-0002-4526-3311

Noskov AK, https://orcid.org/0000-0003-0550-2221

\section{Обоснование}

В связи со стремительным распространением новой коронавирусной инфекции (COVID19) в Российской Федерации (РФ) в 2020 г на базе ФКУЗ Противочумный центр Роспотребнадзора были организованы 70 рабочих мест и прикомандированы специалисты научно-исследовательских противочумных институтов Роспотребнадзора. Однако круглосуточный трехсменный режим работы существенно затрудняет организацию и учет проведенных исследований и увеличивает риск возникновения ошибок.

Цель работы состояла в автоматизации наиболее проблемных этапов выполнения ПЦРисследований на новую коронавирусную инфекцию и разработке алгоритма отслеживания результатов в режиме реального времени.

Материалы и методы. Разработку собственных программных решений проводили на языке Python 3.8.2. 
Результаты и обсуждение. Исходными данными для автоматизации явились файлы xlsx, автоматически генерируемые программным обеспечением амплификатора, и типовые табличные шаблоны, заполняемые на этапах разбора проб и выделения РНК. Разработанное нами программное обеспечение проводило консолидацию данных в единый «файл-реестр» с одновременным выявлением возможных ошибок (наличие дублей, различия в перечнях проб на разных этапах и т.п.). Использование скриптового языка Python обеспечивает кроссплатформенность (возможность работы в любой операционной системе) и позволяет легко и быстро модифицировать систему при изменении каких-либо параметров или структуры входных файлов. Так на разработку и ввод в эксплуатацию данного программного комплекса было затрачено 7 дней, что особенно актуально при работе в условиях ЧС и режима повышенной готовности.

Выводы. Использование разработанного нами подхода обеспечило более быстрое выявление проб, требующих повторного исследования, что в свою очередь сократило время выдачи результатов.

Ключевые слова: COVID-19, ПЦР, ИЛС, Рython, информационная система.

Background In connection with the rapid spread of a new coronavirus infection (COVID-19) in the Russian Federation (RF) in 2020, 70 workplaces were organized on the basis of the FKUZ Antiplague Center of Rospotrebnadzor and specialists from research antiplague institutes of Rospotrebnadzor were seconded. However, the round-the-clock three-shift mode of operation significantly complicates the organization and recording of the studies and increases the risk of errors.

The purpose of the work was to automate the most problematic stages of performing PCR studies for a new coronavirus infection and to develop an algorithm for tracking the results in real time.

Materials and methods. The development of our own software solutions was carried out in Python 3.8.2.

Results and discussion. The initial data for automation were xlsx files automatically generated by the thermocycler software and typical tabular templates filled in at the stages of sample analysis and RNA extraction. The software developed by us consolidated the data into a single "file-register" with the simultaneous identification of possible errors (the presence of duplicates, differences in the lists of samples at different stages, etc.). The use of the Python scripting language provides cross-platform functionality (the ability to work in any operating system) and allows you to easily and quickly modify the system when changing any parameters or the structure of input files. Only 7 days were spent on the 
development and commissioning of this software complex, which is especially important when working in an emergency and high alert mode.

Conclusions. The use of the approach developed by us provided faster identification of samples requiring re-examination, which in turn reduced the time for issuing results.

Keywords: COVID-19, PCR, ILS, Python, information system.

\section{Обоснование}

Одной из важнейших задач обеспечения санитарно-эпидемиологического благополучия населения и эпидемиологического надзора за опасными инфекционными болезнями, особенно в острый период эпидемического распространения, является оперативность лабораторной диагностики. В режиме массового поступления образцов клинического материала на исследование оперативность и корректность регистрации, учета и представления результатов является сложной организационно-технической задачей, особенно при экстренном перепрофилировании организаций на проведение лабораторных исследований в количестве, превышающем расчетные показатели в десятки раз.

По состоянию на 8 сентября 2020 г. в мире зарегистрировано 27248331 лабораторно подтвержденных случаев заражения новым коронавирусом (из них в Российской Федерации 1030690), в том числе 891153 с летальным исходом (из них в Российской Федерации - 17871).

31.12.19 г. Муниципальная комиссия здравоохранения г. Ухань опубликовала сообщение о выявлении 27 случаев пневмонии неясной этиологии. Дальнейшее стремительное развитие эпидемической вспышки новой коронавирусной инфекции (COVID-19) в г. Ухань, провинции Хубэй, Китайской Народной Республики показало высокий эпидемический потенциал новой инфекционной болезни, в связи с чем были введены жесткие ограничительные мероприятия. С января 2020 года в мире началось широкое распространение вируса SARS-CoV-2 возбудителя COVID-19, затронувшее порядка 186 стран. 30 января 2020 года ВОЗ объявила Чрезвычайную ситуацию в области общественного здравоохранения. К концу февраля 2020 г. наблюдалось резкое осложнение эпидемической обстановки по COVID-19 в Южной Корее, Иране и Италии и ряде других стран, и уже 11 марта 2020 г. ВОЗ объявила о начале пандемии новой коронавирусной инфекции. На основании информации по эпидемиологии, клинике и патогенезу и в соответствии с санитарным законодательством Российской Федерации вирус SARS-Cov-2, возбудитель COVID-19, отнесен ко II группе патогенности.

В связи с этим в целях обеспечения санитарно-эпидемиологического благополучия населения Российской Федерации было начато проведение комплекса противоэпидемических мероприятий в рамках санитарной охраны территории Российской Федерации, в частности, 
усиление санитарно-карантинного контроля в пунктах пропуска через государственную границу, направленных на предупреждение завоза и распространения COVID-19 на территории Российской Федерации (Постановление Главного государственного санитарного врача Российской Федерации от 24.01.2020 № 2).

С 25 января 2020 г на базе лабораторий ФКУЗ «Противочумный центр» Роспотребнадзора были развернуты исследования по диагностике COVID-19 в поступающих образцах клинического материала от больных, контактных и с подозрением на заболевание COVID-19, а с 7 февраля 2020 года для обеспечения бесперебойной работы штат был усилен прикомандированными сотрудниками ФКУЗ Российский научно-исследовательский противочумный институт «Микроб», и работа лабораторий была организована уже в круглосуточном режиме.

В этот период среднесуточное поступление составляло порядка 200 проб, что соответствовало пропускной способности лаборатории. Однако с 15 марта в связи с ухудшением эпидемиологической обстановки в г. Москве были начаты масштабные мероприятия по материально-техническому доукомплектованию лабораторной базы Противочумного центра, которые были завершены в кратчайшие сроки. Также для обеспечения бесперебойной круглосуточной работы в условиях массового поступления образцов биологического материала на исследование по приказу Руководителя Федеральной службы по надзору в сфере защиты прав потребителей и благополучия человека в ФКУЗ Противочумный центр Роспотребнадзора были организованы 70 рабочих мест и оперативно прикомандированы специалисты противочумных институтов Роспотребнадзора, имеющие допуск и опыт работы с возбудителями I-IV групп патогенности, с развертыванием мобильных лабораторных модулей СПЭБ (специализированных противоэпидемических бригад) ФКУЗ Ставропольского научноисследовательского противочумного института.

Только за 17 дней в марте 2020 года во ФКУЗ «Противочумный центр» Роспотребнадзора поступило - 35245 проб биологического материала. Среднесуточное поступление составило 2073 пробы. За указанный период было выявлено 1025 положительных и 29793 отрицательных результата. За период с 15 марта по 31 августа в лабораторию ФКУЗ «Противочумный центр» Роспотребнадзора поступило более $200 \quad 000$ тысяч проб биологического материала, из них доля положительных - 53740, что от общего числа составило $-27,5 \%$.

Сложившаяся ситуация являлась уникальной - впервые за много лет РФ столкнулась с глобальным распространением опасной инфекционной болезни, потребовавшей внесения существенных корректив в работу лабораторной службы. 
Основными проблемными вопросами, с которыми столкнулись специалисты лабораторного звена, являлись:

• $\quad$ непрогнозируемое одномоментное поступление однотипных по составу проб биологического материала (носо- и ротоглоточные мазки, патолого-анатомический материал) в количестве, значительно превышающем расчетную суточную мощность лаборатории;

- $\quad$ необходимость строгого временного учета проведения каждого этапа лабораторного исследования конкретной пробы;

- отслеживание каждой пробы от момента поступления до выдачи результата.

Для их решения в ФКУЗ «Противочумный центр» Роспотребнадзора оперативно были проведены организационно-структурные мероприятия, направленные на обеспечение непрерывной поточности в условиях массового поступления биологического материала: проведено кадровое перераспределение для усиления этапов разбора поступивших проб, пробоподготовки, выделения РНК, постановки, учёта и выдачи результатов ПЦР.

Анализ работы в сложившейся ситуации выявил несколько отличительных особенностей. С одной стороны, переход лаборатории в режим диагностики «моно-инфекции» формально упрощает проведение работ. С другой стороны, переход на круглосуточный режим работы приводит к тому, что различные этапы одного и того же анализа проводятся специалистами разных смен, что, в свою очередь, существенно затрудняет организацию и учет проводимых исследований и увеличивает риск возникновения ошибок. В этой связи особую роль приобретает автоматизация процесса учета поступления проб и выдачи результатов с целью как предотвращения, так и раннего выявления возможных ошибок.

В настоящее время для решения схожих вопросов на рынке присутствует большое количество автоматизированных лабораторных информационных систем (ЛИС) созданных для облегчения учета проводимых исследований [1]. Использование готовых коммерческих продуктов несет в себе целый ряд положительных аспектов. Так многие ЛИС предусматривают автоматизацию всех этапов выполнения исследований, начиная от поступления материала и заканчивая выдачей ответа. Не менее актуальным является наличие профессиональной поддержки пользователей и постоянное обновление программного обеспечения с учетом изменяющихся потребностей лаборатории. Однако, использование таких ЛИС несет в себе и ряд недостатков, одним из которых является и достаточно длительный период интеграции и персонификации, а также высокую стоимость специфического оборудования и расходных материалов. Также существенные коррективы при автоматизированном учете вносит работа в режиме диагностики «моно-инфекции» - при этом многие стандартные функции ЛИС, 
направленные на организацию многопрофильной лаборатории, становятся неоправданно избыточными.

В ряде случаев для организации лабораторной работы создаются собственные ЛИС [2]. Это требует наличия в штате IT-специалистов и значительных затрат времени на создание и развертывание системы, однако в этом случае можно более полно учесть все особенности конкретной лаборатории. Разработка собственных программных решений в этом случае позволяет сконцентрировать усилия на автоматизации наиболее проблемных мест.

В связи с вышеизложенным, цель настоящего исследования состояла в автоматизации наиболее проблемных этапов выполнения ПЦР-исследований на новую коронавирусную инфекцию и в разработке алгоритма отслеживания результатов в режиме реального времени.

\section{Материалы и методы}

Исследования на новую коронавирусную инфекцию проводили методом ПЦР с использованием набора реагентов «РеалБест PHK SARS-CoV-2» (AO «Вектор-Бест», Россия) с использованием амплификаторов в режиме реального времени С 1000 Touch с оптическим модулем CFX96 (Bio-Rad, CША). Для контроля режима амплификации и учета результатов применяли программный комплекс "Реал Бест Диагностика" (АО «Вектор-Бест», Россия). Разработку собственных программных решений проводили на языке Python 3.8.2.

\section{Результаты}

Проведение одного ПЦР-исследования на новую коронавирусную инфекцию от момента поступления материала до выдачи ответа, как правило, занимает 5-7 часов. Как уже указывалось, в условиях круглосуточной трехсменной работы лаборатории это требует конвейерной работы, при которой постановку ПЦР и учет результатов могут выполнять разные специалисты в разных сменах. Весьма значимым является фактор гетерогенности материала, поступающего на исследование - так секционный материал требует больше времени на первичную обработку по сравнению с носоглоточным мазком. Немаловажным является необходимость повторного исследования ряда проб при получении сомнительного результата, что так же может выполнятся сотрудниками другой смены. Все это приводит к увеличению времени исследования ряда проб и является потенциальным источником ошибок. В связи с этим было решено сконцентрировать свои усилия на разработке алгоритма, позволяющего отслеживать получение результатов по каждой пробе в режиме реального времени.

Важным требованием, предъявляемым к разрабатываемому алгоритму, явилась необходимость работы с большого числа компьютеров, как непосредственно подключенных к 
амплификаторам, так и находящихся в «чистой зоне» и предназначенных для контроля выдачи результатов.

Довольно актуальным является вопрос выбора языка программирования для реализации разрабатываемого алгоритма. Очевидно, что разрабатываемый программный продукт должен обеспечивать возможность быстрого внесения правок в исходный код в случае изменения требований к программе.

Ранее аналогичное программное обеспечение разрабатывалась нами на базе Microsoft Excel на языке программирования VBA (Visual Basic for Applications), однако на данный момент, ввиду перехода на отечественное программное обеспечение, данный вариант является неприемлемым.

В связи с вышеизложенным мы остановили свой выбор на языке программирования Python, что позволяет работать в любой операционной системе и обеспечивает независимость от наличия пакета Microsoft Office, даже при работе с файлами в формате xlsx (Microsoft Excel). Использование данного формата позволяет работать с программным комплексом широкому кругу лиц без необходимости дополнительного обучения. С этой целью нами были разработаны типовые шаблоны для заполнения на этапах разбора проб и выделения РНК с последующей загрузкой на сетевой диск. На этапе постановки ПЦР и учета амплификации для последующей работы программы используются файлы xlsx, автоматически генерируемые программой "Реал Бест Диагностика", что согласуется с требованиями, предъявляемыми к организации менеджмента качества лабораторных исследований.

После загрузки всех исходных файлов на сетевой диск пользователем проводится запуск программного модуля. В процессе работы программа сводит все получаемые данные воедино (рис.1), проводя проверку как на корректность обозначения проб (буква и цифровой код от 0 до 9999), так и на наличие дублей. Согласно используемой системе менеджмента качества, в одной постановке не может быть двух проб с одинаковой нумерацией, поэтому наличие дубликатов является ошибкой, требующей немедленного исправления.

По итогам работы программы формируется два файла: общий файл, содержащий суммарные данные всех постановок и «файл-реестр», содержащий перечень всех проб с указанием результатов по завершенным исследованиям. Именно «файл-реестр» позволяет получать оперативную информацию о пробах, по которым еще не получены результаты и на которые нужно обратить особое внимание.

Важно отметить, что генерация общего файла и «файла-реестра» каждый раз происходит заново, что весьма актуально при исправлении исходных протоколов после выявления ошибок, что обеспечивает наличие в итоговых файлах только актуальных данных. Время на генерацию таких файлов при загрузке 500 протоколов составляет около 5 секунд. 


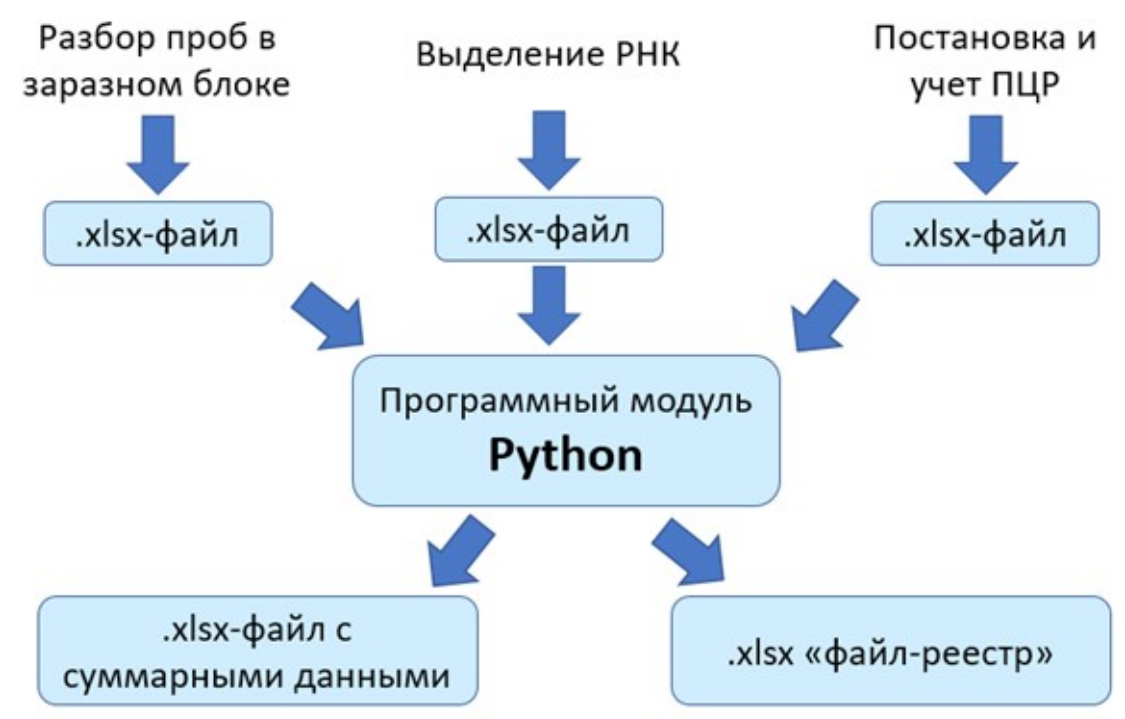

Рисунок 1. Схема работы программного комплекса по автоматической обработке данных

\section{Обсуждение}

Анализ генерируемых файлов направлен на поиск возможных ошибок. Стоит отметить, что одной из возможных ошибок является ошибка в нумерации проб, особенно при наличии повторяющихся цифр (например, обозначение 6886 вместо 6686). Однако при возникновении подобной ошибки, с одной стороны, происходит возникновение «дубля», что возможно выявить в процессе работы программы на этапе формирования общего файла. С другой стороны, при этом в «файле-реестре» будет отсутствовать результат по данной пробе, что хорошо видно при визуальном анализе. Все это позволяет быстро выявлять и исправлять ошибки подобного типа практически сразу после их возникновения.

Использование скриптового языка Python для выполнения задач отслеживания результатов в режиме реального времени в условиях проведения большого объема моноисследований на новую коронавирусную инфекцию обеспечивает кроссплатформенность (возможность работы в любой операционной системе) и позволяет легко и быстро модифицировать систему при изменении каких-либо параметров или структуры входных файлов. Так на разработку и ввод в эксплуатацию данного программного комплекса было затрачено 7 дней, что особенно актуально при работе в условиях ЧС и режима повышенной готовности. При этом использование файлов Microsoft Excel и возможность переноса их с помощью флеш-накопителей обеспечивает возможность одновременной работы с неограниченного числа компьютеров даже при отсутствии доступа к внутренний сети.

\section{Заключение}


Таким образом, в ходе проведенной работы разработан алгоритм выявления ошибок, возникающих при проведении большого числа исследований. Разработано программное обеспечение на языке программирования Python, реализующее данный алгоритм. Созданное программное обеспечение успешно внедрено в практику лабораторной работы ФКУЗ «Противочумный Центр» Роспотребнадзора и, впоследствии успешно использовано во ФКУЗ Ростовский-на-Дону противочумный институт Роспотребнадзора при проведении ПЦРисследований на новую коронавирусную инфекцию в 2020 году.

Использование разработанного нами подхода обеспечило возможность более быстрого выявления технических ошибок, дискордантных результатов и проб требующих повторного исследования, что в свою очередь сократило время выдачи результатов.

\section{Дополнительная информация}

Благодарность. Авторы выражают благодарность заместителю директора ФКУЗ «Противочумный центр» Роспотребнадзора С.M. Ивановой за ценные замечания по оформлению и содержанию статьи.

Источник финансирования. Исследование не имело спонсорской поддержки

Участие авторов. . А.С. Водопьянов - концепция и дизайн исследования; А.С. Водопьянов, Ю.Н. Хомяков, Р.В. Писанов - сбор и обработка материала; А.С. Водопьянов, Ю.Н. Хомяков, А.Ю. Фурина — написание текста; А.С.Водопьянов, Ю.Н. Хомяков, Р.В. Писанов, А.А. Лопатин, А.К.Носков - редактирование; А.А. Лопатин, А.К.Носков утверждение окончательного варианта статьи; А.С. Водопьянов, Ю.Н. Хомяков, ответственность за целостность всех частей статьи.

Все авторы внесли существенный вклад в проведение поисково-аналитической работы и подготовку статьи, прочли и одобрили финальную версию до публикации.

\section{Литература}

Гусев А.В., Новицкий Р.Э. Обзор отечественных лабораторных информационных систем // Врач и информационные технологии.-2008.-№ 2.- С. 24-32. [Gusev AV, Novitsky RE. An overview of domestic laboratory information systems.Vrach i imedicinkiye tehnologii.2008;2; 24-32 (In Russ).]

Андрюков Б.Г., Андрюков И.Б., Гельман Е.А., Ларичев В.Г., Логинова Т.В., Федосеева И.Н. Опыт создания и внедрения лабораторной информационной системы в практику клиникодиагностической лаборатории многопрофильного ведомственного лечебного учреждения // 
Здоровье. Медицинская экология. Наука.-2015.-№ 5-(63)-С. 62-68. [Andryukov BG, Andtyukov IB, Gelman EA et al. 2015;63(5):62-68. (In Russ.).] 